\title{
Biventricular diastolic filling patterns after coronary artery bypass graft surgery
}

\author{
Yanfen Shi, MD, ${ }^{c}$ André Y. Denault, MD, ${ }^{\text {a }}$ Pierre Couture, MD, ${ }^{a}$ Ady Butnaru, MD, ${ }^{\mathrm{c}}$ Michel Carrier, MD, \\ and Jean-Claude Tardif, MD, FACC ${ }^{\mathrm{C}}$
}

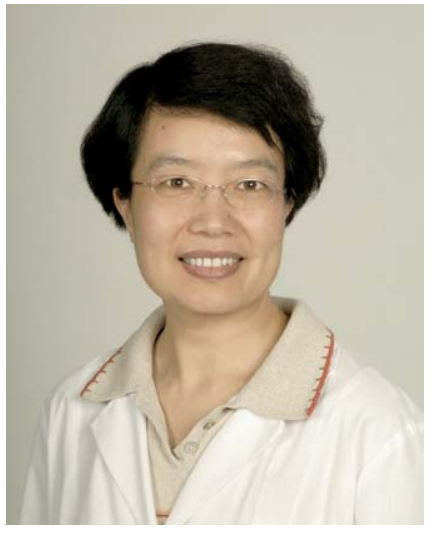

Dr Shi

? Supplemental material is available online.

From the Departments of Anesthesia, ${ }^{\text {a }}$ Surgery, ${ }^{\mathrm{b}}$ and Medicine, ${ }^{\mathrm{c}}$ Montreal Heart Institute, and University of Montreal, Montreal, Quebec, Canada.

Supported by the Montreal Heart Institute Foundation and by the 2001 Dr Earl Wynands Research Award in Cardiovascular Anesthesia.

Received for publication Sept 27, 2005; revisions received Jan 10, 2006; accepted for publication Jan 13, 2006.

Address for reprints: Jean-Claude Tardif, MD, Montreal Heart Institute, $5000 \mathrm{Be}-$ langer St, Montreal, QC H1T 1C8, Canada (E-mail: jean-claude.tardif@icm-mhi.org).

J Thorac Cardiovasc Surg 2006;131:1080-6

$0022-5223 / \$ 32.00$

Copyright $\odot 2006$ by The American Association for Thoracic Surgery

doi:10.1016/j.jtcvs.2006.01.015
Objective: We sought to study the evolution of biventricular filling properties after coronary artery bypass grafting.

Background: The evolution of diastolic function as defined with newer echocardiographic modalities after coronary artery bypass grafting surgery is unknown in patients with preoperative left ventricular diastolic dysfunction.

Methods: Transthoracic echocardiography was performed preoperatively and 48 hours and 6 months after coronary artery bypass grafting in 49 patients (randomized to milrinone $[\mathrm{n}=25]$ ) or placebo $[\mathrm{n}=24]$ ) with preoperative left ventricular diastolic dysfunction classified according to published criteria. Mild right ventricular diastolic dysfunction was defined as the ratio of early to atrial filling velocity of less than 1 in transtricuspid flow or the velocity of reversed atrial flow of greater than $50 \%$ of that of systolic flow in hepatic venous flow or the ratio of tricuspid annulus velocity during early and atrial filling of less than 1 if both the ratio of early to atrial filling velocity and the ratio of systolic to diastolic velocity was greater than 1 in hepatic venous flow. Moderate right ventricular diastolic dysfunction was diagnosed when there was a ratio of early to atrial filling velocity of greater than 1 with a ratio of systolic to diastolic velocity of less than 1 . Severe right ventricular diastolic dysfunction was defined as a ratio of early to atrial filling velocity of greater than 1 associated with reversed systolic wave in hepatic venous flow.

Results: Moderate and severe left ventricular diastolic dysfunction increased from preoperatively to 48 hours after coronary artery bypass grafting from $8.2 \%$ to $53.7 \%$ and from $2.0 \%$ to $9.7 \%$, respectively $(P<.0001,48$ hours vs preoperatively for both), and the patterns at 6 months were similar to those observed preoperatively. Similar evolution over time was found for right ventricular diastolic dysfunction.

Conclusions: In patients with preoperative left ventricular diastolic dysfunction, biventricular filling patterns are impaired initially but return to preoperative status 6 months after coronary artery bypass grafting.

A bnormalities in left ventricular diastolic function are prevalent in adult cardiac surgical patients. ${ }^{1}$ Preoperative left ventricular diastolic dysfunction (LVDD) increases the risk of complications in cardiac surgery, ${ }^{2}$ and a restrictive pattern is associated with higher early postoperative mortality and morbidity and minimal improvement in left ventricular systolic function in patients undergoing coronary artery bypass grafting (CABG) surgery. ${ }^{3,4}$ A pseudonormal or restrictive left ventricular filling pattern shortly after $\mathrm{CABG}$ predicts detrimental left ventricular remodeling and cardiac events in the long term after the operation. ${ }^{4}$ Previous studies on the effect of CABG on left ventricular diastolic function have had conflicting results. ${ }^{5,6}$ The long-term influence of CABG on ventricular diastolic performance is not well known. Furthermore, much less attention was paid to right 


$$
\begin{array}{ll}
\text { Abbreviations and Acronyms } \\
\text { A } & =\text { atrial filling A-wave velocity } \\
\mathrm{Am} & =\text { late mitral annular velocity } \\
\mathrm{Ar} & =\text { reversed atrial flow } \\
\mathrm{At} & =\text { atrial filling tricuspid annular velocity } \\
\mathrm{CABG} & =\text { coronary artery bypass grafting } \\
\mathrm{CPB} & =\text { cardiopulmonary bypass } \\
\mathrm{D} & =\text { diastolic D-wave velocity } \\
\mathrm{DT} & =\text { E-wave deceleration time } \\
\mathrm{E} & =\text { early mitral filling E-wave velocity } \\
\mathrm{Em} & =\text { early mitral annular velocity } \\
\mathrm{Et} & =\text { early filling tricuspid annular velocity } \\
\mathrm{HVF} & =\text { hepatic venous flow } \\
\mathrm{IVRT} & =\text { isovolumic relaxation time } \\
\mathrm{LVDD} & =\text { left ventricular diastolic dysfunction } \\
\mathrm{LVEF} & =\text { left ventricular ejection fraction } \\
\mathrm{PVF} & =\text { pulmonary venous flow } \\
\mathrm{PW} & =\text { pulsed wave } \\
\mathrm{RVDD} & =\text { right ventricular diastolic dysfunction } \\
\mathrm{S} & =\text { systolic S-wave velocity } \\
\mathrm{TDI} & =\text { tissue Doppler imaging } \\
\mathrm{TMF} & =\text { transmitral flow } \\
\mathrm{TTF} & =\text { transtricuspid flow } \\
\mathrm{Vp} & =\text { propagation velocity } \\
&
\end{array}
$$

ventricular diastolic profile in this population. Therefore this study aimed to evaluate the short- and long-term evolution of biventricular diastolic performance in patients with preoperative LVDD undergoing CABG surgery with the newer echocardiographic modalities and the more recent classification recommended by the American Society of Echocardiography. ${ }^{7,8}$ In addition, we also wanted to document whether milrinone, an agent commonly used in cardiac surgery, had persistent effects on diastolic dysfunction after treatment interruption.

\section{Methods}

After obtaining approval from the Research and Ethics Committees of the Montreal Heart Institute and informed consent, 49 of 70 consecutive patients undergoing elective CABG surgery with cardiopulmonary bypass (CPB) and preoperative LVDD diagnosed by means of echocardiography were studied prospectively. Patients were excluded if they had a pacemaker or if they were not in sinus rhythm because of the difficulty in interpreting diastolic function indexes in such patients. The patients were randomized to milrinone $(n=25)$ or placebo $(n=24)$ as part of a study on the intraoperative effect of milrinone, an agent commonly used in cardiac surgery. The dosage of milrinone consisted of a bolus of 50 $\mu \mathrm{g} / \mathrm{kg}$ followed by a perfusion of $0.5 \mu \mathrm{g} \mathrm{kg}^{-1} \cdot \mathrm{min}^{-1}$ started after the induction of anesthesia and continuing until skin closure.

\section{Transthoracic Echocardiography}

Serial transthoracic echocardiographic studies were performed preoperatively and 48 hours and 6 months after CABG surgery by using harmonic imaging with a $2.5-\mathrm{MHz}$ phased-array transducer and a standard echocardiographic system (Sonos 5500; Hewlett-Packard, Andover, Mass). As shown in Figure 1, an apical 4-chamber view was recorded to measure left and right endsystolic atrial area and left and right ventricular end-diastolic areas. Pulsed-wave (PW) Doppler imaging was used to evaluate transmitral flow (TMF), transtricuspid flow (TTF), pulmonary venous flow (PVF), and hepatic venous flow (HVF). Peak velocities in early filling (E) and atrial filling (A) were measured, and the E/A ratio was calculated in TMF and TTF; the peak velocities of systolic flow (S), diastolic flow (D), and reversed atrial flow (Ar) were measured in PVF and HVF, and the S/D ratio was calculated. Left ventricular isovolumic relaxation time (IVRT) was measured with continuous-wave Doppler scanning at the conjunction of left ventricular inflow and outflow and was corrected by the square root of R-R interval (IVRT/[RR $]^{1 / 2}$ ) on simultaneously recorded electrocardiograms. Mitral annulus velocities during early filling (Em) and atrial filling (Am) and those of the tricuspid annulus (Et, At) were derived by means of tissue Doppler imaging (TDI), and mitral flow propagation velocity $(\mathrm{Vp})$ was studied with color M-mode scanning, as previously described. ${ }^{7,9}$ Ratios of E/Em and $\mathrm{E} / \mathrm{Vp}$ were calculated for the left ventricle. The average of 3 consecutive cardiac cycles was used for each measurement. Special care was taken to obtain similar imaging planes on serial examinations by reviewing the previous recordings before the follow-up study for each patient.

To validate our measurements, we subjected 10 echocardiograms to 3 repeated measurements in a blinded fashion, with 3 consecutive cardiac cycles analyzed for each recording. The coefficient of variation (SD $\div$ mean $\times 100 \%$ ) between 3 consecutive cardiac cycles of the 10 echocardiograms was $2.7 \% \pm 1.6 \%$ and $4.5 \% \pm 1.8 \%$ for the left and right atrial areas in cardiac systole and $3.4 \% \pm 1.4 \%$ and $4.4 \% \pm 1.9 \%$ for the left and right ventricular end-diastolic areas, respectively. For PW velocity, IVRT, TDI velocity, and $\mathrm{Vp}$, the coefficients of variation were $5.4 \% \pm$ $2.6 \%, 3.8 \% \pm 1.6 \%, 2.6 \% \pm 1.3 \%$, and $7.6 \% \pm 3.5 \%$, respectively. The coefficient of variation between the 3 results based on the average of 3 cycles of these 10 echocardiograms was $1.4 \% \pm$ $0.8 \%$ and $2.7 \% \pm 1.8 \%$ for the left and right atrial areas in cardiac systole and $2.9 \% \pm 1.1 \%$ and $2.9 \% \pm 1.1 \%$ for the left and right ventricular end-diastolic areas, respectively. For PW velocity, IVRT, TDI velocity, and $\mathrm{Vp}$, the coefficients of variation were $1.1 \% \pm 0.4 \%, 1.2 \% \pm 0.4 \%, 1.0 \% \pm 1.0 \%$, and $3.0 \% \pm 1.4 \%$, respectively.

LVDD was classified according to published criteria. ${ }^{8}$ Mild LVDD was defined by an E/A ratio of less than 1 in TMF or $1<$ E/A $<2$ with an S/D ratio of greater than 1 in PVF and an Em of less than $12.5 \mathrm{~cm} / \mathrm{s}$ with Am greater than $12.5 \mathrm{~cm} / \mathrm{s}$. Moderate LVDD was considered present when the E/A ratio was greater than 1 with an S/D ratio of less than 1. Severe LVDD was diagnosed when the E/A ratio was greater than 2 with an S/D ratio of less than 1. Right ventricular diastolic evaluation was based on a combination of transtricuspid and hepatic venous PW Doppler signals and tricuspid annulus TDI signals. ${ }^{10}$ Mild right ventricular diastolic dysfunction (RVDD) was defined by an E/A ratio of less than 1 in $\mathrm{TTF}$ or an E/A ratio of greater than 1 and an S/D ratio of greater than 1 in HVF if the Ar wave was greater than $50 \%$ of $\mathrm{S}$ in HVF or the Et/At ratio was less than 1. Moderate RVDD was considered 
A

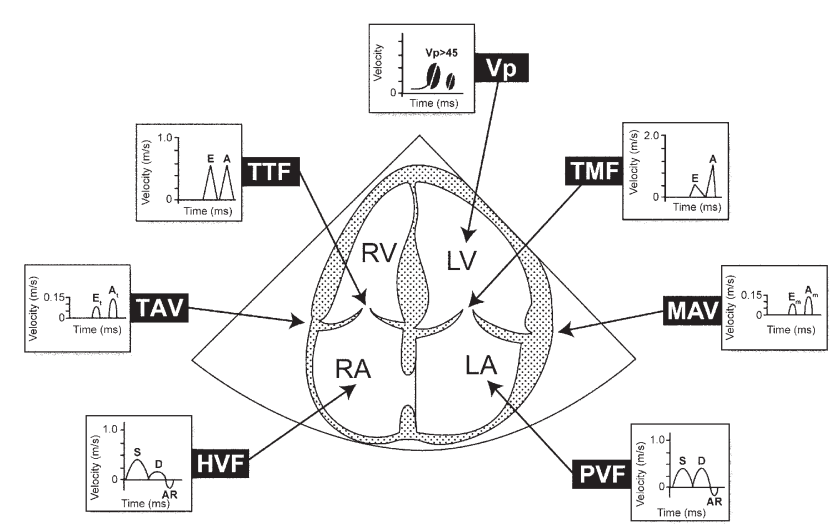

B

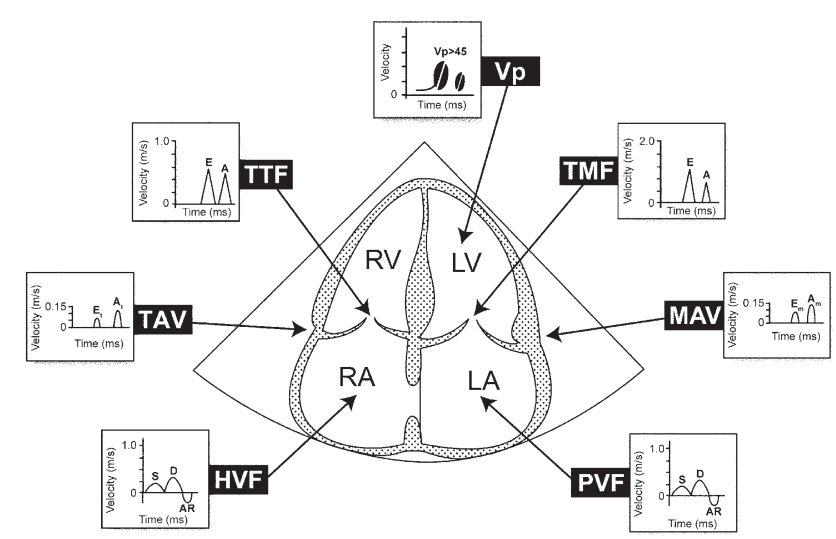

C

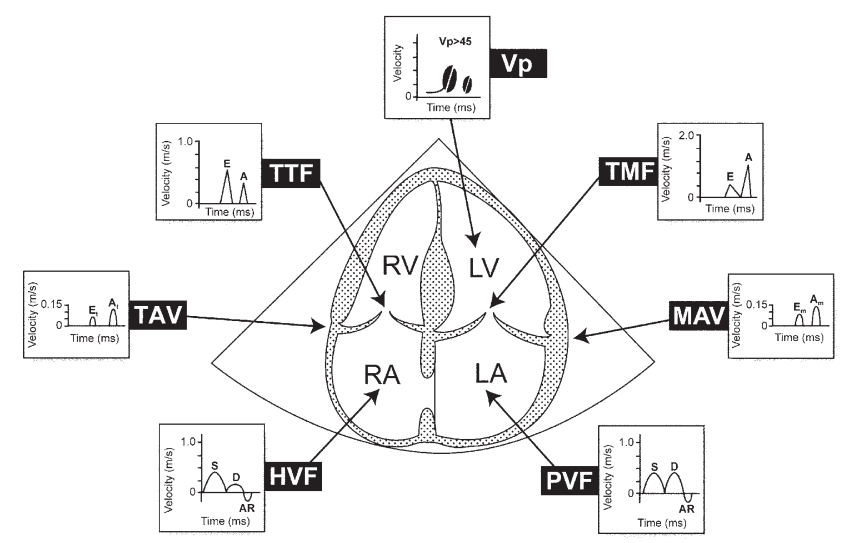

Figure 1. Changes in biventricular cardiac dimensions and in Doppler profiles before (A) and 48 hours (B) and 6 months (C) after coronary revascularization. At 48 hours, an increase in both the left and right atrial size is observed. This is associated with a deterioration in both the left and right ventricular diastolic parameters. At 6 months, no significant difference is seen compared with the preoperative echocardiographic parameters. HVF, Hepatic venous flow; $L A$, left atrium; $L V$, left ventricle; $M A V$, mitral annular velocities; $P V F$, pulmonary venous flow; $R A$, right atrium; $R V$, right ventricle; $T M F$, transmitral flow; $\Pi T F$, transtricuspid flow; $V p$, velocity of propagation. present when the E/A ratio was greater than 1 with an S/D ratio of less than 1. Severe RVDD was diagnosed when an E/A ratio of greater than 1 was associated with reversal of the $S$ wave in HVF.

\section{Statistical Analysis}

All data are expressed as means \pm SD. To analyze the evolution of the variables, mixed-model repeated-measures analyses of covariance controlling for the baseline value ${ }^{11}$ were used to extract the group $\times$ time interaction and the time and group main effects. When the group $\times$ time interaction was significant, which means that groups showed a significant difference in evolution, slice effect (also known as simple effect) ${ }^{12}$ analyses were performed to evaluate differences among groups at each time level and to test the evolution of each group. These analyses were performed with the mixed procedure of SAS 6.12 to handle missing data. A $P$ value less than .05 was considered statistically significant. The Wilcoxon test was used to compare the distribution of frequencies of both left and right ventricular diastolic function patterns $(P<$ .0167 was considered significant).

\section{Results}

Of the 49 patients studied, 37 were male and aged from 55 to 81 years ( $68.6 \pm 7.3$ years), and 12 were female and aged from 51 to 81 years $(69.0 \pm 9.5)$, with no significant age difference between male and female patients. The mean Parsonnet score ${ }^{13}$ was $10 \pm 5$, and the mean preoperative left ventricular ejection fraction (LVEF) was $50 \% \pm 14 \%$, with 5 patients having LVEFs of less than $30 \%$. A total of 52 thoracic grafts and 111 venous grafts were performed during CABG surgery. The mean bypass and crossclamp times were $74 \pm 22$ and $46 \pm 18$ minutes, respectively. Aprotinin was used in all patients, and a cold blood cardioplegia technique was used.

Heart rate and body weight were significantly increased (from $65.9 \pm 11.6$ to $81.4 \pm 15.2$ beats/min and $80.4 \pm$ 15.4 to $83.1 \pm 13.9 \mathrm{~kg}[\mathrm{n}=45]$, respectively), and systolic and diastolic blood pressure were significantly decreased (from $125.5 \pm 12.8$ to $115.4 \pm 10.6$ and $66.3 \pm 8.6$ to $60.6 \pm 7.3 \mathrm{~mm} \mathrm{Hg}[\mathrm{n}=45]$, respectively) postoperatively, and they all returned to baseline levels at 6 months' follow-up. There was no significant difference in urea/ creatinine, creatine kinase, creatine kinase MB, and troponin values between the milrinone and placebo groups at any stage over the study course. One patient died in each group. The main findings of our study are summarized in Figure 1.

\section{Left Ventricular Diastolic Patterns}

In the preoperative period the distribution of LVDD as assessed by the newer classification modalities described above was $0 \%, 89.8 \%, 8.2 \%$, and $2.0 \%(\mathrm{n}=49)$ for normal, mild, moderate, and severe LVDD, respectively. It was $0 \%$, $36.6 \%, 53.7 \%$, and $9.7 \%(\mathrm{n}=41)$ and $4.5 \%, 91.0 \%, 4.5 \%$, and $0 \%(\mathrm{n}=23)$ at 48 hours and 6 months after CABG surgery, respectively $(P<.0001$ at 48 hours vs preoperatively and 6 months). No significant difference in the degree 
of LVDD was observed between preoperative and 6-month evaluations, and no effect of milrinone was observed.

Cardiac chamber size over the study course derived from 2-dimensional echocardiography. Both left and right atrial areas were significantly increased postoperatively and returned to baseline levels at 6 months' follow-up (from $20.3 \pm 3.4$ to $24.5 \pm 4.8$ to $21.8 \pm 4.4 \mathrm{~cm}^{2}$ and from $15.5 \pm$ 3.1 to $19.5 \pm 4.2$ to $15.9 \pm 3.9 \mathrm{~cm}^{2}, P<.05$ for 48 hours vs preoperatively and 6 months). No significant changes in the left and right ventricular size were found during the study course. There was no significant difference in the cardiac chamber size between the milrinone and placebo groups at any stage over the study course, and the 2 groups shared the same evolution.

Transmitral inflow pattern (Table E1). The transmitral E wave significantly increased and the A wave decreased, leading to an increased $\mathrm{E} / \mathrm{A}$ ratio, and $\mathrm{E}$-wave deceleration time (DT) significantly shortened at 48 hours after CABG. These changes returned to baseline levels 6 months after the operation. A shorter A-wave duration $(P=.047)$ was observed at 6 months compared with that seen in the preoperative study. The milrinone group had a higher E/A ratio and a shorter A-wave duration than the placebo group at all stages during the study course. However, the 2 groups shared the same evolution.

Pulmonary venous flow (Table E2). At 48 hours after CABG surgery, the D wave in the pulmonary vein significantly increased, leading to a decreased S/D ratio $(P<$ .0001) postoperatively. The 6-month values returned to their baseline levels. A shorter Ar-wave duration was found at 48 hours after $\mathrm{CABG}$, and this remained unchanged 6 months after the operation.

Mitral annulus velocities (Em and Am) derived by TDI (Table E3). No significant changes were observed for Em, Am, or Em/Am ratio during the whole study course. The milrinone group had a higher Em and Em/Am ratio at baseline and at all stages during the study course compared with the placebo group. However, the 2 groups shared the same evolution. E/Em ratio significantly increased at 48 hours $(P=.03)$ and was lower at 6 months compared with baseline $(P=.02)$ and 48 -hour $(P=.001)$ values. No significant difference in $\mathrm{E} / \mathrm{Em}$ ratio was observed between the milrinone and placebo groups.

Left ventricular IVRT (Table E4). The evolution of left ventricular IVRT derived from continuous-wave Doppler imaging and its heart rate-corrected value are described in Table E4. Both shortened 48 hours after CABG $(P<.05$ for both) and returned to baseline levels at 6 months. There was no significant difference in IVRT between the milrinone and placebo groups at any stage over the study course, and the 2 groups shared the same evolution.

Mitral flow Vp (Table E4). There were important increases in Vp 48 hours after CABG $(P<.05$ vs baseline), and the values returned toward preoperative levels 6 months after. E/Vp significantly decreased 48 hours after CABG and returned toward baseline 6 months later.

Right ventricular diastolic patterns. The distribution of normal, mild, moderate, and severe RVDD was $0 \%, 91.3 \%$, $6.5 \%$, and $2.2 \%(\mathrm{n}=46)$ preoperatively; $2.6 \%, 53.8 \%$, $20.5 \%$, and $23.1 \%(\mathrm{n}=39)$ at 48 hours; and $9.1 \%, 86.4 \%$, $4.5 \%$, and $0 \%(\mathrm{n}=22)$ at 6 months $(P=.002$ for 48 hours vs preoperatively and $P=.01$ for 48 hours vs 6 months). No significant difference in the degree of RVDD was observed between the preoperative and 6-month evaluations. Milrinone had no effect on the evolution of right ventricular diastolic filling patterns.

Transtricuspid inflow (Table E5). The transtricuspid E wave significantly increased at 48 hours and stayed at this high level 6 months after CABG surgery. Significantly shorter E-wave deceleration times were observed at both the 48-hour and 6-month evaluations compared with those at the preoperative study $(P<.05)$. There was a higher E/A ratio in the milrinone group than in the placebo group at baseline and at all stages during the study course, and the 2 groups shared the same evolution.

Hepatic venous flow (Table E6). The $\mathrm{S}$ wave and the S/D ratio significantly decreased from baseline to 48 hours after CABG. There was no significant difference in any of the parameters studied in HVF between the milrinone and placebo groups at any stage over the study course, and the 2 groups shared the same evolution.

Tricuspid annulus velocities derived from TDI (Table E7). The tricuspid annulus velocities Et and At significantly decreased at 48 hours after CABG surgery, and they stayed at this lower level 6 months later. An increased Et/At ratio was observed at 48 hours after CABG and returned to preoperative levels 6 months later. There was no significant difference in Et, At, and Et/At ratio between the milrinone and placebo groups at any stage over the study course, and the 2 groups shared the same evolution.

\section{Discussion}

Our study showed that in patients with LVDD before CABG, both left and right ventricular diastolic performance were impaired early after $\mathrm{CABG}$ surgery but returned to preoperative filling status 6 months after CABG, as assessed by using the newer echocardiographic modalities to classify diastolic function. This evolution is not altered with intraoperative milrinone.

\section{Studies on Left Ventricular Diastolic Function in Patients Undergoing CABG}

Doppler echocardiography has been used in previous studies to evaluate left ventricular filling in patients undergoing CABG surgery, with quite similar findings but conflicting interpretation of postoperative left ventricular diastolic function. Lawson and colleagues ${ }^{5}$ observed increased $\mathrm{E}$ waves 
and decreased A waves 1 week after CABG, which were of the same order as we found at 48 hours. Those investigators concluded that $\mathrm{CABG}$ resulted in normalization of early filling and decreased reliance on active atrial transport, implying improved left ventricular diastolic function by CABG. In the study of van der Maaten and colleagues, ${ }^{14}$ increased $\mathrm{E}$ and $\mathrm{A}$ waves were observed postoperatively and returned to baseline values 4 hours after $\mathrm{CABG}$, but changes in these velocities did not result in decreased E/A ratios. They concluded that diastolic function was preserved after CABG surgery in patients with preserved left ventricular systolic function. In selected patients with good preoperative systolic left ventricular function, Houltz and associates $^{15}$ found that the E/A ratio was unchanged during CABG and concluded that both the active and passive components of left ventricular diastolic function are well maintained shortly after CABG and cardioplegic arrest. In another study ${ }^{16}$ TMF and PVF were evaluated by means of transesophageal echocardiography, and the evolution of the E- and A-wave velocities over time was similar to those observed in our study. Djaiani and coworkers ${ }^{17}$ used Vp to identify patients with abnormal diastolic function during CABG surgery. They studied TMF and PVF profiles, as well as IVRT; found that LV filling patterns did not change significantly after $\mathrm{CPB}$; and concluded that $\mathrm{Vp}$ of less than $50 \mathrm{~cm} / \mathrm{s}$ identified abnormal diastolic function in this patient population. In the study of Gorcsan and colleagues ${ }^{18}$ on TMF in patients undergoing CABG, left ventricular diastolic function worsened shortly after CABG surgery but improved at 20 hours follow-up. In a study by Wehlage and coworkers, ${ }^{6}$ the contribution of early diastolic filling to left ventricular filling decreased from $55 \%$ to $35 \%$ during surgical intervention. Furthermore, Ekery and associates ${ }^{19}$ reported that LVDD after CABG is a frequent finding of clinical significance that persists at least 3 hours after the operation. Finally, in another study ${ }^{20}$ changes in myocardial velocities derived by using TDI indicated impairment in left ventricular diastolic function immediately after CABG.

The assessment of changes in left ventricular diastolic function after CABG surgery in these previous studies, however, was based on interpretation of individual echocardiographic parameters, and diastolic function was not classified according to the newer criteria. Most of the individual Doppler echocardiographic parameters are heart rate and load dependent, and the integration of the different changes in diastolic parameters must be performed for correct interpretation. Normalization of one parameter, such as TMF, taken in isolation could indicate improved or deteriorating diastolic function, such as that observed in a pseudonormal pattern. ${ }^{8}$ Our study is therefore the first to use a combination of 2-dimensional, pulsed Doppler echocardiography and the newer echocardiographic modalities to classify diastolic function. We found that 48 hours after CABG surgery, left atrial dilatation, changes in TMF profile, increased $\mathrm{E}$ and E/A ratio, shortened deceleration time, and decreased S/D ratio revealed a shift of filling patterns from delayed relaxation to pseudonormal or restrictive patterns. The increase of $\mathrm{E} / \mathrm{Em}$ ratio, which is used to estimate left ventricular enddiastolic pressure at 48 hours, supports this deterioration of left ventricular diastolic function. Our study also found that the mitral Vp increased at 48 hours. A pseudonormal filling pattern and an LVEF of greater than $60 \%$ have been found to be significant predictors of false-negative results with $\mathrm{Vp}$ in predicting LVDD $(P<.05),{ }^{21}$ which could explain this finding.

\section{Studies on Right Ventricular Diastolic Function in Patients Undergoing CABG}

Perioperative right ventricular function is another potential predictor of postoperative morbidity and mortality for patients undergoing CABG surgery. ${ }^{22,23}$ It is well known that CABG surgery can impair right ventricular systolic function, ${ }^{24}$ and right ventricular systolic dysfunction is associated with a high in-hospital mortality rate. ${ }^{25}$ However, the effect of CABG on the natural evolution of right ventricular diastolic properties using all the available echocardiographic modalities has not been described. Alam and colleagues ${ }^{26}$ used TDI to study right ventricular diastolic filling before and after CABG and found that Et was significantly reduced 1 month and 1 year after CABG. However, evaluation of HVF, which provides unique insight into right ventricular dynamics, was not recorded. Reduced S/D ratio immediately after $\mathrm{CABG}$ has been correlated with increased pulmonary artery diastolic and RA pressure after CABG surgery. ${ }^{27,28}$ In our study, using 2-dimensional echocardiographic and Doppler-derived HVF, TTF, and TDI values, we observed that right ventricular diastolic filling was impaired early after CABG surgery but improved 6 months later. Indeed, early postoperative right ventricular diastolic deterioration was associated with right atrial dilatation and abnormal TTF, HFV, and TDI values. Despite persistent increased TTF E waves, shortened deceleration time, and decreased Et after CABG surgery, there was normalization of right atrial dimensions and HVF at 6 months. Improvement in HVF was also observed 6 months after CABG surgery by Wranne and coworkers. ${ }^{29}$ These changes in biventricular diastolic function could be explained by several structural and dynamic factors, ${ }^{30}$ including the cardioplegia solution, ${ }^{17,31}$ the intraoperative ischemia commonly associated with relaxation abnormalities, ${ }^{5}$ and possibly reperfusion injury. ${ }^{31}$

\section{Effect of Milrinone}

Milrinone was administered intraoperatively, and no difference was observed in the postoperative evolution of biventricular diastolic properties. Phosphodiesterase inhibitors improve the response to $\beta$-adrenergic drugs and can poten- 
tiate the effects of dobutamine. ${ }^{32}$ In addition, milrinone has been demonstrated to improve diastolic performance in patients with congestive heart failure, ${ }^{33}$ left ventricular compliance after $\mathrm{CPB},{ }^{34,35}$ and cardiac output and myocardial performance measured with transesophageal echocardiography. ${ }^{35,36}$ The absence of a residual effect on diastolic function at 48 hours could be explained by the short-term use of this drug in the operating room.

\section{Limitations}

Hemodynamic data were not obtained together with echocardiographic evaluation of diastolic profiles. Our conclusions apply to patients undergoing elective coronary revascularization during $\mathrm{CPB}$ with preoperative LVDD. The patients were followed up for 6 months, and therefore a more marked effect of CABG on diastolic performance might have been seen with a longer follow-up. The pericardium was left open after CABG surgery in this group of patients, which could influence biventricular filling patterns. However, no significant effect was observed in a study by Lindstrom and colleagues, ${ }^{37}$ in which a pericardial patch was used.

\section{References}

1. Lappas DG, Skubas NJ, Lappas GD, Ruocco E, Tambassis E, Pasque M. Prevalence of left ventricular diastolic filling abnormalities in adult cardiac surgical patients: an intraoperative echocardiographic study. Semin Thorac Cardiovasc Surg. 1999;11:125-33.

2. Bernard F, Denault AY, Babin D, Goyer C, Couture P, Couturier A, et al. Diastolic dysfunction is predictive of difficult weaning from cardiopulmonary bypass. Anesth Analg. 2001;92:291-8.

3. Vaskelyte J, Stoskute N, Kinduris S, Ereminiene E. Coronary artery bypass grafting in patients with severe left ventricular dysfunction: predictive significance of left ventricular diastolic filling pattern. Eur J Echocardiogr. 2001;2:62-7.

4. Liu J, Tanaka N, Murata K, Ueda K, Wada Y, Oyama R, et al. Prognostic value of pseudonormal and restrictive filling patterns on left ventricular remodeling and cardiac events after coronary artery bypass grafting. Am J Cardiol. 2003;91:550-4.

5. Lawson WE, Seifert F, Anagnostopoulos C, Hills DJ, Swinford RD, Cohn PF. Effect of coronary artery bypass grafting on left ventricular diastolic function. Am J Cardiol. 1988;61:283-7.

6. Wehlage DR, Bohrer H, Ruffmann K. Impairment of left ventricular diastolic function during coronary artery bypass grafting. Anaesthesia. 1990;45:549-51.

7. Garcia MJ, Palac RT, Malenka DJ, Terrell P, Plehn JF. Color M-mode Doppler flow propagation velocity is a relatively preload-independent index of left ventricular filling. J Am Soc Echocardiogr. 1999;12: 129-37.

8. Khouri SJ, Maly GT, Suh DD, Walsh TE. A practical approach to the echocardiographic evaluation of diastolic function. J Am Soc Echocardiogr. 2004;17:290-7.

9. Denault AY, Couture P, Tardif JC, Buithieu J. Transesophageal echocardiography multimedia manual: a perioperative transdisciplinary approach. Oxford: Marcel Dekker; 2005.

10. Klein AL, Hatle LK, Burstow DJ, Taliercio CP, Seward JB, Kyle RA, et al. Comprehensive Doppler assessment of right ventricular diastolic function in cardiac amyloidosis. J Am Coll Cardiol. 1990;15:99-108.

11. Fleiss JL. Statistical methods for rates and proportions. 2nd ed. New York: Wiley; 1981

12. Winer BJ. Statistical principles in experimental design. 2nd ed. New York: McGraw-Hill; 1971
13. Bernstein AD, Parsonnet V. Bedside estimation of risk as an aid for decision-making in cardiac surgery. Ann Thorac Surg. 2000;69:823-8.

14. van der Maaten JM, De Vries AJ, Henning RH, Epema AH, van den Berg MP, Lip H. Effects of preoperative treatment with diltiazem on diastolic ventricular function after coronary artery bypass graft surgery. J Cardiothorac Vasc Anesth. 2001;15:710-6.

15. Houltz E, Hellstrom A, Ricksten SE, Wikh R, Caidahl K. Early effects of coronary artery bypass surgery and cold cardioplegic ischemia on left ventricular diastolic function: evaluation by computer-assisted transesophageal echocardiography. J Cardiothorac Vasc Anesth. 1996; 10:728-33.

16. Oppizzi M, Zoia E, Franco A, Gerli C, Vendrame G, Guarracino F, et al. Diastolic dysfunction in cardiac surgery intensive care. Study methods, changes and prognosis. Minerva Anestesiol. 1997;63:29-38.

17. Djaiani GN, McCreath BJ, Ti LK, Mackensen BG, Podgoreanu M, Phillips-Bute B, et al. Mitral flow propagation velocity identifies patients with abnormal diastolic function during coronary artery bypass graft surgery. Anesth Analg. 2002;95:524-30.

18. Gorcsan J III, Diana P, Lee J, Katz WE, Hattler BG. Reversible diastolic dysfunction after successful coronary artery bypass surgery. Assessment by transesophageal Doppler echocardiography. Chest. 1994; 106:1364-9.

19. Ekery DL, Davidoff R, Orlandi QG, Apstein CS, Hesselvik JF, Shemin RJ, et al. Imaging and diagnostic testing: diastolic dysfunction after coronary artery bypass grafting: a frequent finding of clinical significance not influenced by intravenous calcium. Am Heart J. 2003;145: 896-902.

20. Skarvan K, Filipovic M, Wang J, Brett W, Seeberger M. Use of myocardial tissue Doppler imaging for intraoperative monitoring of left ventricular function. Br J Anaesth. 2003;91:473-80.

21. Palecek T, Linhart A, Bultas J, Aschermann M. Comparison of early diastolic mitral annular velocity and flow propagation velocity in detection of mild to moderate left ventricular diastolic dysfunction. Eur J Echocardiogr. 2004;5:196-204.

22. Reichert CL, Visser CA, van den Brink RB, Koolen JJ, van Wexel HB, Moulijn AC, et al. Prognostic value of biventricular function in hypotensive patients after cardiac surgery as assessed by transesophageal echocardiography. J Cardiothorac Vasc Anesth. 1992;6:429-32.

23. Maslow AD, Regan MM, Panzica P, Heindel S, Mashikian J, Comunale ME. Precardiopulmonary bypass right ventricular function is associated with poor outcome after coronary artery bypass grafting in patients with severe left ventricular systolic dysfunction. Anesth Analg. 2002:95:1507-18.

24. Hedman A, Alam M, Zuber E, Nordlander R, Samad BA. Decreased right ventricular function after coronary artery bypass grafting and its relation to exercise capacity: a tricuspid annular motion-based study. $J$ Am Soc Echocardiogr. 2004;17:126-31.

25. Davila-Roman VG, Waggoner AD, Hopkins WE, Barzilai B. Right ventricular dysfunction in low output syndrome after cardiac operations: assessment by transesophageal echocardiography. Ann Thorac Surg. 1995;60:1081-6.

26. Alam M, Hedman A, Nordlander R, Samad B. Right ventricular function before and after an uncomplicated coronary artery bypass graft as assessed by pulsed wave Doppler tissue imaging of the tricuspid annulus. Am Heart J. 2003;146:520-6.

27. Nomura T, Lebowitz L, Koide Y, Keehn L, Oka Y. Evaluation of hepatic venous flow using transesophageal echocardiography in coronary artery bypass surgery: an index of right ventricular function. J Cardiothorac Vasc Anesth. 1995;9:9-17.

28. Mishra M, Swaminathan M, Malhotra R, Mishra A, Trehan N. Evaluation of right ventricular function during $\mathrm{CABG}$ : transesophageal echocardiographic assessment of hepatic venous flow versus conventional right ventricular performance indices. Echocardiography. 1998; 15:51-8.

29. Wranne B, Pinto FJ, Hammarstrom E, St Goar FG, Puryear J, Popp RL. Abnormal right heart filling after cardiac surgery: time course and mechanisms. Br Heart J. 1991;66:435-42.

30. Apstein CS, Lorell BH. The physiological basis of left ventricular diastolic dysfunction. J Card Surg. 1988;3:475-85.

31. Vinten-Johansen J, Nakanishi K. Postcardioplegia acute cardiac dysfunction and reperfusion injury. J Cardiothorac Vasc Anesth. 1993;7:6-18. 
32. Gage J, Rutman H, Lucido D, LeJemtel TH. Additive effects of dobutamine and amrinone on myocardial contractility and ventricular performance in patients with severe heart failure. Circulation. 1986; 74:367-73

33. Monrad ES, McKay RG, Baim DS, Colucci WS, Fifer MA, Heller GV, et al. Improvement in indexes of diastolic performance in patients with congestive heart failure treated with milrinone. Circulation. 1984;70: 1030-7.

34. Lobato EB, Gravenstein N, Martin TD. Milrinone, not epinephrine, improves left ventricular compliance after cardiopulmonary bypass. J Cardiothorac Vasc Anesth. 2000;14:374-7.
35. Lobato EB, Florete O Jr, Bingham HL. A single dose of milrinone facilitates separation from cardiopulmonary bypass in patients with pre-existing left ventricular dysfunction. Br J Anaesth. 1998;81:782-4.

36. Kikura M, Levy JH, Michelsen LG, Shanewise JS, Bailey JM, Sade $\mathrm{SM}$, et al. The effect of milrinone on hemodynamics and left ventricular function after emergence from cardiopulmonary bypass. Anesth Analg. 1997;85:16-22.

37. Lindstrom L, Wigstrom L, Dahlin LG, Aren C, Wranne B. Lack of effect of synthetic pericardial substitute on right ventricular function after coronary artery bypass surgery. An echocardiographic and mag netic resonance imaging study. Scand Cardiovasc J. 2000;34:331-8. 
TABLE E1. Transmitral inflow-derived variables

\begin{tabular}{|c|c|c|c|c|c|c|}
\hline & \multirow[b]{2}{*}{$\mathbf{n}$} & \multicolumn{3}{|c|}{ Peak velocity $(\mathrm{cm} / \mathrm{s})$} & \multirow[b]{2}{*}{ DT (ms) } & \multirow[b]{2}{*}{ A duration (ms) } \\
\hline & & E wave & A wave & E/A ratio & & \\
\hline \multicolumn{7}{|l|}{ Preoperative } \\
\hline Total & 46 & $68.3 \pm 17.0$ & $83.3 \pm 21.6$ & $0.88 \pm 0.39$ & $255.6 \pm 51.3$ & $136.0 \pm 18.7$ \\
\hline Milrinone & 22 & $73.7 \pm 16.9$ & $79.2 \pm 18.2$ & $0.97 \pm 0.30 \ddagger$ & $243.1 \pm 55.1$ & $130.9 \pm 17.6 \ddagger$ \\
\hline Placebo & 24 & $62.3 \pm 14.9$ & $85.1 \pm 24.3$ & $0.81 \pm 0.46$ & $263.5 \pm 45.2$ & $141.0 \pm 19.8$ \\
\hline \multicolumn{7}{|l|}{$48 \mathrm{~h}$} \\
\hline Total & 44 & $85.2 \pm 19.1^{*}$ & $70.8 \pm 17.6^{*}$ & $1.27 \pm 0.47^{*}$ & $183.1 \pm 50.0^{*}$ & $121.8 \pm 16.5^{*}$ \\
\hline Milrinone & 21 & $85.9 \pm 18.9^{*}$ & $64.5 \pm 17.0^{*}$ & $1.44 \pm 0.57^{*} \ddagger$ & $174.2 \pm 43.6^{*}$ & $118.4 \pm 17.0^{*} \ddagger$ \\
\hline Placebo & 23 & $84.6 \pm 19.7^{*}$ & $77.1 \pm 16.1^{*}$ & $1.11 \pm 0.25^{*}$ & $191.6 \pm 55.2^{*}$ & $125.3 \pm 15.7^{*}$ \\
\hline \multicolumn{7}{|l|}{$6 \mathrm{mo}$} \\
\hline Total & 21 & $65.1 \pm 14.0 \dagger$ & $81.7 \pm 16.3$ & $0.82 \pm 0.21 \dagger$ & $236.3 \pm 42.3 \dagger$ & $127.9 \pm 19.9 \S$ \\
\hline Milrinone & 9 & $67.4 \pm 7.8 \dagger$ & $82.7 \pm 15.2$ & $0.86 \pm 0.26 \dagger \ddagger$ & $244.1 \pm 47.5 \dagger$ & $122.4 \pm 21.3 \pm \S$ \\
\hline Placebo & 12 & $63.3 \pm 17.4 \dagger$ & $80.9 \pm 17.8$ & $0.79 \pm 0.17 \dagger$ & $230.4 \pm 39.2 \dagger$ & $131.9 \pm 18.6 \S$ \\
\hline
\end{tabular}

E, Early mitral filling E-wave velocity; $A$, atrial filling A-wave velocity; $D T$, E-wave deceleration time. $* P<.05$ for 48 hours versus preoperative stage. $\dagger P<.05$ for 6 months versus 48 hours. $\ddagger P<.05$ between treatment groups. $\S P<.05$ for 6 months versus preoperative stage.

TABLE E2. Pulmonary venous flow-derived variables

\begin{tabular}{|c|c|c|c|c|c|c|}
\hline & \multirow[b]{2}{*}{ n } & \multicolumn{3}{|c|}{ Peak velocity $(\mathrm{cm} / \mathrm{s})$} & \multirow[b]{2}{*}{$\mathrm{Ar}$} & \multirow{2}{*}{$\begin{array}{l}\text { Ar duration } \\
\text { (ms) }\end{array}$} \\
\hline & & S wave & D wave & S/D & & \\
\hline \multicolumn{7}{|l|}{ Preoperative } \\
\hline Total & 45 & $50.1 \pm 12.3$ & $44.7 \pm 12.4$ & $1.19 \pm 0.43$ & $29.6 \pm 5.0$ & $114.3 \pm 27.8$ \\
\hline Milrinone & 22 & $50.2 \pm 10.0$ & $44.7 \pm 13.6$ & $1.19 \pm 0.31$ & $30.0 \pm 5.3$ & $108.9 \pm 27.2$ \\
\hline Placebo & 23 & $50.1 \pm 14.7$ & $44.2 \pm 12.1$ & $1.22 \pm 0.53$ & $29.5 \pm 4.9$ & $116.1 \pm 23.1$ \\
\hline \multicolumn{7}{|l|}{$48 \mathrm{~h}$} \\
\hline Total & 41 & $46.4 \pm 12.4$ & $55.0 \pm 14.6^{*}$ & $0.87 \pm 0.29 *$ & $27.9 \pm 7.4$ & $93.7 \pm 24.1^{*}$ \\
\hline Milrinone & 20 & $47.8 \pm 15.2$ & $55.5 \pm 11.6^{*}$ & $0.89 \pm 0.33^{*}$ & $28.1 \pm 8.9$ & $102.6 \pm 26.3^{*}$ \\
\hline Placebo & 21 & $45.1 \pm 9.3$ & $54.6 \pm 17.2^{*}$ & $0.86 \pm 0.22^{*}$ & $27.8 \pm 6.0$ & $85.2 \pm 18.7^{*}$ \\
\hline \multicolumn{7}{|l|}{$6 \mathrm{mo}$} \\
\hline Total & 20 & $53.4 \pm 13.2$ & $43.3 \pm 8.2 \dagger$ & $1.25 \pm 0.27 \dagger$ & $27.3 \pm 5.4$ & $91.4 \pm 18.6 \ddagger$ \\
\hline Milrinone & 9 & $57.9 \pm 11.7$ & $45.3 \pm 10.1 \dagger$ & $1.31 \pm 0.25 \dagger \ddagger$ & $28.0 \pm 6.9$ & $94.7 \pm 25.1 \ddagger$ \\
\hline Placebo & 11 & $49.7 \pm 13.7$ & $41.6 \pm 6.3 \dagger$ & $1.20 \pm 0.29 \dagger \ddagger$ & $26.7 \pm 4.0$ & $88.4 \pm 10.6 \ddagger$ \\
\hline
\end{tabular}

$S$, Systolic S-wave velocity; $D$, diastolic-D wave velocity; $A r$, reversed A-wave velocity. $* P<.05$ for 48 hours versus preoperative stage. $\dagger P<.05$ for 6 months versus 48 hours. $\ddagger P<.05$ for 6 months versus preoperative stage.

TABLE E3. Tissue Doppler imaging velocities from lateral mitral annulus

\begin{tabular}{|c|c|c|c|c|c|}
\hline & $\mathbf{n}$ & $\mathrm{Em}(\mathrm{cm} / \mathrm{s})$ & $\mathrm{Am}(\mathrm{cm} / \mathrm{s})$ & Em/Am ratio & $\mathrm{E} / \mathrm{Em}$ ratio (n) \\
\hline \multicolumn{6}{|l|}{ Preoperative } \\
\hline Total & 46 & $8.5 \pm 2.3$ & $11.7 \pm 3.2$ & $0.76 \pm 0.25$ & $8.6 \pm 3.2(43)$ \\
\hline Milrinone & 22 & $9.0 \pm 2.4 \ddagger$ & $11.5 \pm 2.8$ & $0.81 \pm 0.20 \ddagger$ & $8.6 \pm 2.8(21)$ \\
\hline Placebo & 24 & $8.1 \pm 2.4$ & $12.0 \pm 3.7$ & $0.73 \pm 0.30$ & $8.4 \pm 3.6(22)$ \\
\hline \multicolumn{6}{|l|}{$48 \mathrm{~h}$} \\
\hline Total & 41 & $9.3 \pm 2.0$ & $12.1 \pm 3.9$ & $0.87 \pm 0.43$ & $9.8 \pm 3.2^{*}(39)$ \\
\hline Milrinone & 19 & $9.8 \pm 2.2 \ddagger$ & $10.8 \pm 2.9$ & $1.02 \pm 0.53 \ddagger$ & $9.6 \pm 3.1^{*}(19)$ \\
\hline Placebo & 22 & $8.9 \pm 1.8$ & $13.2 \pm 4.4$ & $0.74 \pm 0.27$ & $9.9 \pm 3.3^{*}(20)$ \\
\hline \multicolumn{6}{|l|}{$6 \mathrm{mo}$} \\
\hline Total & 21 & $9.3 \pm 1.7$ & $11.8 \pm 2.9$ & $0.83 \pm 0.26$ & $7.2 \pm 1.9+\S(21)$ \\
\hline Milrinone & 9 & $10.6 \pm 1.1 \ddagger$ & $11.8 \pm 2.4$ & $0.93 \pm 0.23 \ddagger$ & $6.5 \pm 1.0 \dagger \S(9)$ \\
\hline Placebo & 12 & $8.4 \pm 1.6$ & $11.8 \pm 3.3$ & $0.77 \pm 0.27$ & $7.7 \pm 2.3+\S(12)$ \\
\hline
\end{tabular}

$E m$, Early mitral annular velocity; $A m$, Late mitral annular velocity; $E$, early trans-mitral filling E-wave velocity. $* P<.05$ for 48 hours versus preoperative stage. $\dagger P<.05$ for 6 months versus 48 hours. $\ddagger P<.05$ between treatment groups. $\S P<.05$ for 6 months versus preoperative stage and 48 hours. 
TABLE E4. Left ventricular isovolumic relaxation time and mitral valve propagation velocity

\begin{tabular}{|c|c|c|c|c|c|c|}
\hline & $\mathbf{n}$ & IVRT, IVRT//RR) $)^{1 / 2}(\mathrm{~ms})$ & $n$ & $V p(\mathrm{~cm} / \mathrm{s})$ & $\mathrm{E} / \mathrm{Np}$ ratio & $\mathbf{n}$ \\
\hline \multicolumn{7}{|l|}{ Preoperative } \\
\hline Total & 46 & $103.0 \pm 23.6,3.32 \pm 0.73$ & 43 & $47.1 \pm 17.7$ & $1.56 \pm 0.61$ & 46 \\
\hline Milrinone & 22 & $97.0 \pm 17.8,3.07 \pm 0.51$ & 21 & $45.3 \pm 11.3$ & $1.71 \pm 0.65$ & 22 \\
\hline Placebo & 24 & $107.3 \pm 28.1,3.48 \pm 0.86$ & 22 & $50.6 \pm 22.3$ & $1.34 \pm 0.50$ & 24 \\
\hline \multicolumn{7}{|l|}{$48 \mathrm{~h}$} \\
\hline Total & 45 & $71.7 \pm 14.1^{*}, 2.66 \pm 0.54$ & 40 & $78.6 \pm 27.3^{*}$ & $1.18 \pm 0.44^{*}$ & 40 \\
\hline Milrinone & 21 & $71.1 \pm 13.2^{*}, 2.62 \pm 0.54^{*}$ & 19 & $70.2 \pm 16.0^{*}$ & $1.27 \pm 0.37^{*}$ & 19 \\
\hline Placebo & 24 & $72.2 \pm 15.1^{*}, 2.69 \pm 0.55^{*}$ & 21 & $86.3 \pm 33.1^{*}$ & $1.09 \pm 0.50^{*}$ & 21 \\
\hline \multicolumn{7}{|l|}{$6 \mathrm{mo}$} \\
\hline Total & 21 & $94.0 \pm 14.9 \dagger, 3.18 \pm 0.51$ & 21 & $55.1 \pm 20.4 \dagger$ & $1.30 \pm 0.44$ & 21 \\
\hline Milrinone & 9 & $91.2 \pm 13.0 \dagger, 3.13 \pm 0.59 \dagger$ & 9 & $57.1 \pm 24.4 \dagger$ & $1.33 \pm 0.42$ & 9 \\
\hline Placebo & 12 & $96.0 \pm 16.4 \dagger, 3.21 \pm 0.47 \dagger$ & 12 & $53.6 \pm 17.8 \dagger$ & $1.28 \pm 0.47$ & 12 \\
\hline
\end{tabular}

$I V R T$, Isovolumic relaxation time; $R R, \mathrm{R}-\mathrm{R}$ interval in milliseconds derived from simultaneously recorded electrocardiograms; $V p$, propagation velocity; $E$, early mitral filling E-wave velocity. $* P<.05$ for 48 hours versus preoperative stage. $\dagger P<.05$ for 6 months versus 48 hours.

TABLE E5. Transtricuspid inflow-derived variables

\begin{tabular}{|c|c|c|c|c|c|}
\hline & \multirow[b]{2}{*}{ n } & \multicolumn{3}{|c|}{ Peak velocity $(\mathrm{cm} / \mathrm{s})$} & \multirow[b]{2}{*}{ DT (ms) } \\
\hline & & E wave & A wave & E/A ratio & \\
\hline \multicolumn{6}{|l|}{ Preoperative } \\
\hline Total & 44 & $47.2 \pm 9.8$ & $46.1 \pm 12.6$ & $1.06 \pm 0.24$ & $229.7 \pm 56.1$ \\
\hline Milrinone & 20 & $48.2 \pm 9.1$ & $45.9 \pm 14.0$ & $1.11 \pm 0.26 \ddagger$ & $236.7 \pm 71.0$ \\
\hline Placebo & 24 & $45.9 \pm 10.7$ & $46.3 \pm 11.5$ & $1.02 \pm 0.22$ & $223.8 \pm 43.6$ \\
\hline \multicolumn{6}{|l|}{$48 \mathrm{~h}$} \\
\hline Total & 41 & $53.6 \pm 11.8^{*}$ & $48.5 \pm 14.4$ & $1.16 \pm 0.31$ & $184.5 \pm 52.3^{*}$ \\
\hline Milrinone & 19 & $53.0 \pm 13.0^{*}$ & $45.4 \pm 13.4$ & $1.23 \pm 0.34 \ddagger$ & $190.8 \pm 59.1^{*}$ \\
\hline Placebo & 22 & $54.1 \pm 10.8^{*}$ & $51.5 \pm 15.1$ & $1.09 \pm 0.26$ & $179.0 \pm 46.3^{*}$ \\
\hline \multicolumn{6}{|l|}{$6 \mathrm{mo}$} \\
\hline Total & 21 & $55.0 \pm 10.2 \S$ & $41.2 \pm 7.1$ & $1.37 \pm 0.33 \dagger \S$ & $174.1 \pm 44.9 \S$ \\
\hline Milrinone & 9 & $58.6 \pm 9.2 \S$ & $41.0 \pm 6.9$ & $1.46 \pm 0.32 \dagger \ddagger \S$ & $177.9 \pm 41.8 \S$ \\
\hline Placebo & 12 & $52.3 \pm 10.4 \S$ & $41.4 \pm 7.6$ & $1.30 \pm 0.32 † \S$ & $171.2 \pm 48.9 \S$ \\
\hline
\end{tabular}

$E$, Early tricuspid filling E-wave velocity; $A$, atrial filling A-wave velocity; $D T$, tricuspid E-wave deceleration time. $* P<.05$ for 48 hours versus preoperative stage. $\dagger P<.05$ for 6 months versus 48 hours. $\ddagger P<.05$ between treatment groups. $\S P<.05$ for 6 months versus preoperative stage.

TABLE E6. Hepatic venous flow-derived velocities

\begin{tabular}{|c|c|c|c|c|c|}
\hline & \multirow[b]{2}{*}{$\mathbf{n}$} & \multicolumn{3}{|c|}{ Peak velocity $(\mathrm{cm} / \mathrm{s})$} & \multirow[b]{2}{*}{ Ar } \\
\hline & & S wave & D wave & S/D & \\
\hline \multicolumn{6}{|l|}{ Preoperative } \\
\hline Total & 36 & $49.6 \pm 21.0$ & $38.3 \pm 14.3$ & $1.30 \pm 0.37$ & $33.1 \pm 8.5$ \\
\hline Milrinone & 19 & $50.2 \pm 18.4$ & $39.9 \pm 15.0$ & $1.31 \pm 0.35$ & $32.5 \pm 11.3$ \\
\hline Placebo & 17 & $49.4 \pm 25.3$ & $36.3 \pm 14.0$ & $1.31 \pm 0.40$ & $33.8 \pm 5.3$ \\
\hline \multicolumn{6}{|l|}{$48 \mathrm{~h}$} \\
\hline Total & 17 & $34.4 \pm 12.5^{*}$ & $42.8 \pm 18.7$ & $0.85 \pm 0.35^{*}$ & $29.5 \pm 8.0$ \\
\hline Milrinone & 10 & $34.3 \pm 11.5^{*}$ & $40.6 \pm 23.9$ & $0.82 \pm 0.40^{*}$ & $29.1 \pm 8.0$ \\
\hline Placebo & 7 & $34.6 \pm 14.8^{*}$ & $42.8 \pm 18.7$ & $0.90 \pm 0.27^{*}$ & $29.8 \pm 8.4$ \\
\hline \multicolumn{6}{|l|}{$6 \mathrm{mo}$} \\
\hline Total & 19 & $47.1 \pm 26.3 \dagger$ & $38.8 \pm 25.2$ & $1.26 \pm 0.28 \dagger$ & $30.3 \pm 8.5$ \\
\hline Milrinone & 8 & $60.8 \pm 32.9 \dagger$ & $50.3 \pm 34.5$ & $1.27 \pm 0.20 \dagger$ & $32.4 \pm 7.4$ \\
\hline Placebo & 11 & $37.1 \pm 15.2 \dagger$ & $30.6 \pm 11.3$ & $1.25 \pm 0.33 \dagger$ & $28.7 \pm 9.3$ \\
\hline
\end{tabular}

$S$, Systolic S-wave velocity; $D$, diastolic $D$-wave velocity; $A r$, reversed A-wave velocity. $* P<.05$ for 48 hours versus preoperative stage. $\dagger P<.05$ for 6 months versus 48 hours. 
TABLE E7. TDI velocities from lateral tricuspid annulus

\begin{tabular}{|c|c|c|c|c|}
\hline & $n$ & Et $(\mathrm{cm} / \mathrm{s})$ & At $(\mathrm{cm} / \mathrm{s})$ & Et/At ratio \\
\hline \multicolumn{5}{|l|}{ Preoperative } \\
\hline Total & 46 & $9.3 \pm 2.7$ & $14.9 \pm 3.8$ & $0.63 \pm 0.11$ \\
\hline Milrinone & 22 & $9.6 \pm 2.1$ & $15.7 \pm 3.4$ & $0.62 \pm 0.10$ \\
\hline Placebo & 24 & $9.3 \pm 3.2$ & $14.5 \pm 4.3$ & $0.64 \pm 0.12$ \\
\hline \multicolumn{5}{|l|}{$48 \mathrm{~h}$} \\
\hline Total & 37 & $7.3 \pm 2.5^{*}$ & $9.3 \pm 3.1^{*}$ & $0.83 \pm 0.36^{*}$ \\
\hline Milrinone & 17 & $7.2 \pm 2.5^{*}$ & $9.0 \pm 2.9^{*}$ & $0.88 \pm 0.46^{*}$ \\
\hline Placebo & 20 & $7.5 \pm 2.5^{*}$ & $9.7 \pm 3.2^{*}$ & $0.78 \pm 0.25^{*}$ \\
\hline \multicolumn{5}{|l|}{$6 \mathrm{mo}$} \\
\hline Total & 19 & $6.4 \pm 1.3 \ddagger$ & $10.2 \pm 1.9 \ddagger$ & $0.64 \pm 0.18 \dagger$ \\
\hline Milrinone & 9 & $6.0 \pm 1.1 \ddagger$ & $9.8 \pm 1.8 \ddagger$ & $0.62 \pm 0.13 \dagger$ \\
\hline Placebo & 10 & $6.8 \pm 1.3 \ddagger$ & $10.6 \pm 1.9 \ddagger$ & $0.66 \pm 0.22 \dagger$ \\
\hline
\end{tabular}

TDI, Tissue Doppler imaging; Et, early filling tricuspid annular velocity; $A t$, atrial filling tricuspid annular velocity. $* P<.05$ for 48 hours versus preoperative stage. $\dagger P<.05$ for 6 months versus 48 hours. $\ddagger P<.05$ for 6 months versus preoperative stage. 